\title{
Effects of an introduced polychaete, Sabella spallanzanii, on the development of epifaunal assemblages
}

\author{
Michael G. Holloway*, Michael J. Keough \\ Department of Zoology, University of Melbourne, Melbourne, Victoria 3010, Australia
}

\begin{abstract}
Increasing awareness of the ecological and economic problems caused by marine introductions has brought calls for the development of predictive models of their impacts on other species. We examined the effects of an introduced marine polychaete, Sabella spallanzanii (Gmelin, 1791), on the development of subtidal marine epifaunal assemblages. As an invader of hard subtidal substrata, S. spallanzanii alters the structure of the habitat by forming a canopy of filamentous feeding structures suspended above the substratum on long, slender tubes. As resident species (including S. spallanzanii) can strongly affect the recruitment of sessile taxa into these assemblages, we predicted that one of the effects of this introduction would be to change the relative abundances of understorey species and hence the assemblage structure. In this study we aimed to determine whether the effects of $S$. spallanzanii on sessile assemblages would be apparent after periods of 2 or $6 \mathrm{mo}$, and to evaluate the mechanisms underlying any of such observed effects. Further experiments on individual taxa were done to assess the influence of this exotic species on growth rate and mortality of sessile invertebrates as possible reasons for observed effects. The abundances of 9 taxa were affected by the presence of $S$. spallanzanii after $10 \mathrm{wk}$ of assemblage development on cleared and canopy-covered areas. Multivariate analyses showed that assemblages beneath canopies were significantly different from those outside canopies. After 6 mo, however, there were few differences between canopy-covered and cleared areas, and assemblages did not differ. We found little evidence that $S$. spallanzanii canopies could affect already established assemblages. There were significant effects of the S. spallanzanii canopy on survival and growth rates of epifaunal taxa, although the results were not consistent among experiments, suggesting temporal variability in the processes that cause such changes. There are several implications of these results for the assessment of the impacts of exotic species, including the appropriate choice of timescale over which to conduct experiments and the generality of such experiments.
\end{abstract}

KEY WORDS: Introduced species $\cdot$ Impact $\cdot$ Epifauna $\cdot$ Sabella spallanzanii $\cdot$ Recruitment $\cdot$ Assemblage development

\section{INTRODUCTION}

The problem of marine introductions has received considerable attention in recent years (Carlton 1989,

*Present address: Centre for Research on Ecological Impacts of Coastal Cities, Marine Ecology Laboratories, A11, University of Sydney, New South Wales 2006, Australia.

E-mail: mhollowa@bio.usyd.edu.au
Carlton \& Geller 1993). Such introductions can cause major ecological change, which is sometimes accompanied by substantial economic costs (Williamson 1996). Species introductions have also been cited as the second largest threat to global biodiversity, after habitat conversion (Simberloff 2000). Marine introductions are poorly understood in comparison to their terrestrial counterparts. There is therefore an urgent need to understand various aspects of marine species 
introductions, such as mechanisms of introduction, the apparent susceptibility of particular areas to invasion, why some species become invasive and what the potential impacts of particular species may be (Williamson 1999). In order to understand and make predictions about the ecological impacts of biological invasions, we need to understand the mechanisms by which changes are brought about.

There are 2 prerequisites to gaining a predictive understanding of the mechanisms underlying the ecological effects of invasions. First, one must have a reasonable understanding of the processes that structure the particular assemblage of interest. Second, it is necessary to understand how introduced species interact with or modify those processes. It is important to understand the effects of exotic species in the context of entire assemblages of organisms that are invaded. Exotic species affect local assemblages by a range of mechanisms, including competition, predation, habitat modification, parasitism, provision of new prey, or as pathogens (Crooks 1998, Ruiz et al. 1999, Byers 2000). Some species may cause changes by multiple mechanisms (e.g. the European crab Carcinus maenas: Cohen et al. 1995).

Sessile epifaunal assemblages have been the subject of many studies of the processes that structure them (e.g. McDougal 1943, Osman 1977, Sutherland \& Karlson 1977, Keough \& Butler 1979, Kay \& Keough 1981, Keough 1984a,b, Anderson \& Underwood 1994, Underwood \& Anderson 1994, Osman \& Whitlatch 1995a,b, Brown \& Swearingen 1998, Butler \& Connolly 1999, Glasby 2000). Therefore the processes structuring these assemblages are probably as well understood as those of any ecological assemblage. In a previous study we showed that the canopy formed by the feeding fans of the introduced sabellid polychaete Sabella spallanzanii (Gmelin, 1791) strongly affects the recruitment of sessile invertebrates over a period of 2 wk (Holloway \& Keough 2002). This is consistent with a number of studies that have shown the effects of residents on settlement and recruitment of epifauna (Sutherland \& Karlson 1977, Breitburg 1985, Bros 1987, Bertness 1989, Osman et al. 1989, Duggins et al. 1990, Osman \& Whitlatch 1995a,b, but see Keough 1998).

However, patterns of species abundances formed by recruitment in the first few weeks of assemblage development may or may not persist in the longer term. Patterns of relative abundance may persist when assemblages are recruitment-limited and densities of individuals are so low that competition does not occur (Keough 1984b, Connell 1985). Patterns may also persist if early recruits are competitively superior and hold the available space against later arrivals (e.g. Sutherland \& Karlson 1977). Alternatively, initial patterns of recruitment may be modified or completely obliterated by various post-recruitment processes such as competitive interactions, mortality of short-lived early colonists over longer time periods, or predation, leaving no trace of the original pattern (e.g. Dean 1981, Kay \& Keough 1981).

Competition for space is an important process that structures epifaunal assemblages post-recruitment (Jackson 1977, 1979, Osman 1977, Sutherland \& Karlson 1977, Russ 1980, Kay \& Keough 1981). Encrusting organisms such as colonial ascidians, bryozoans and sponges are often superior competitors for space due to their capacity for indeterminate growth, which allows them to overgrow and kill other species (Jackson 1977 , Kay \& Keough 1981, Keough 1984a). So, although they may be less abundant early in assemblage development, these species may come to dominate the assemblage over time through overgrowth of less competitive taxa. Some species may become dominant because of their ability to invade established assemblages, and to escape from competition by rapid vertical growth (Jackson 1977). Sabella spallanzanii is one of these species, and reaches very high densities without occupying much space on the substratum. Direct effects of $S$. spallanzanii are therefore unlikely, but this species may indirectly affect competitive interactions among understorey taxa.

Indirect effects on post-recruitment processes may be caused by modification of the physical structure of the habitat by residents. Complex habitat structure may modify the effects of predators (Russ 1980). Canopy-forming species like macro-algae or seagrass may cause physical changes such as shading or reduction of flow to the habitat (Eckman et al. 1989, Gambi et al. 1990). Changes to small-scale hydrodynamic regimes may also be caused by biological activities such as suspension feeding in the case of sessile invertebrates (André \& Rosenberg 1991, Ahn et al. 1993, André et al. 1993). Changes to flow may have a range of effects on suspension feeding, food availability, sedimentation rate and effects of the supply of larvae to the substratum. All of these factors could affect the recruitment and subsequent growth and survival of other organisms in these habitats (e.g. Okamura 1984, 1985, Young \& Chia 1984, Eckman \& Duggins 1991, Wendt 1998). Such changed conditions may favour certain species over others by, for example, altering their relative growth rates or survivorship (Eckman \& Duggins 1991).

A number of studies have shown that suspension feeders living in dense aggregations grow more slowly than solitary individuals or colonies (Buss 1981, Okamura 1992, Dalby 1995, Kim \& Lasker 1997). There is also some evidence for the in situ depletion of food resources caused by the feeding activities of corals, ascidian and bryozoan assemblages, sabellid poly- 
chaete aggregations and bivalves (Glynn 1973, Buss \& Jackson 1981, Merz 1984, Fréchette \& Bourget 1985). Thus dense aggregations of suspension feeders may have the ability to pre-empt suspended food resources before they can reach the substratum. Competition for food may cause changes in the growth, survival and competitive ability of sessile suspension feeders.

We have shown that Sabella spallanzanii affects the $2 \mathrm{wk}$ recruitment patterns of sessile marine invertebrates in locations where it occurs in high densities (Holloway \& Keough 2002). In this paper we examine the effect of the introduced fanworm $S$. spallanzanii on sessile assemblages over time periods long enough for post-recruitment processes to influence assemblage structure. To understand how this exotic species will impact the sessile assemblage in the longer term, we examined: (1) whether patterns of difference beneath fanworm canopies are observed after $10 \mathrm{wk}$ and 6 mo periods and, if so, what the underlying mechanisms are; (2) whether S. spallanzanii canopies can influence the composition and structure of already established assemblages. Canopies may affect the sessile assemblage by modifying survivorship and growth of individual taxa. We evaluated this potential mechanism by testing for effects of the canopy on survivorship and growth of 3 common epifaunal taxa.

\section{MATERIALS AND METHODS}

Study species. Sabella spallanzanii (Gmelin, 1791) has been translocated to several locations across southern Australia and throughout the world, outside its native range in the Mediterranean. Its amenity to translocation and ability to invade new areas make it an important species to study (Talman et al. 1999). $S$. spallanzanii was first recorded in Australia in Port Phillip Bay in 1992 (Carey \& Watson 1992), but may have been present there since at least 1988 (Parry et al. 1996). This large, sessile, tubiculous fanworm colonises both hard and soft subtidal substrata, forming dense beds (up to hundreds of ind. per $\mathrm{m}^{2}$ ). The tubes can be up to $40 \mathrm{~cm}$ long and the diameter of the spiralled feeding fan reaches 10 to $15 \mathrm{~cm}$. The tree-like morphology (sensu Jackson 1977), with the feeding fan on top of the long, slender tube makes it unique among the marine fauna of southern Australia. The only other comparably large sabellid in the region, Sabellastarte indica, is shorter and does not occur in high densities. The density and morphology of Sabella spallanzanii result in the formation of a canopy of feeding fans at some distance from the substratum. In areas where it has invaded sessile epifaunal assemblages, S. spallanzanii occupies very little space on the substratum, which is inhabited by a range of common epifaunal taxa including solitary and colonial ascidians, barnacles, bryozoans and bivalves (Talman et al. 1999).

Study sites. The experiments on assemblage development were done in a marina at Outer Harbour, near Adelaide, in South Australia. The marina opens to the northwest into a $600 \mathrm{~m}$ by $3.5 \mathrm{~km}$ artificial channel containing commercial shipping berths. A second breakwater, just inside the entrance of the marina, provides further protection from wave action. The marina was constructed from floating docks anchored to vertical concrete pilings, which were heavily colonised by Sabella spallanzanii at densities of around $250 \mathrm{~m}^{-2}$. Other common taxa in the marina included the encrusting bryozoan Schizoporella sp., colonial ascidians such as Botrylloides perspicuus, and B. leachi, the solitary ascidian Ciona intestinalis, the barnacles Elminius modestus and Balanus variegatus, and serpulid and spirorbid polychaetes. The depth in the marina ranges from 3 to $6 \mathrm{~m}$.

Experiments on the effect of Sabella spallanzanii canopies on growth of sessile understorey invertebrates were done at St Kilda Marina on the eastern side of Port Phillip Bay, near the centre of Melbourne. The marina is enclosed, with a depth of 1.5 to $2 \mathrm{~m}$. It is connected by a narrow channel opening to the northwest, with an underground channel providing further water exchange to the south. The density of $S$. spallanzanii on floating docks in the marina was $311 \pm 20 \mathrm{~m}^{-2}$ (mean $\pm \mathrm{SE}$ ). Other common sessile taxa were Ciona intestinalis, the small sponge Leucosolenia sp., the protist Microfolicullina sp., serpulids, spirorbids, and solitary and colonial ascidian species. Newly recruited understorey animals were collected at St Kilda marina, and at Breakwater Pier, Williamstown. Breakwater Pier is located at the northwestern corner of Port Phillip Bay, close to the centre of Melbourne (see Todd \& Keough 1994, Keough \& Raimondi 1995 for descriptions).

Assemblage development experiments. Two experiments were done at Outer Harbour (hereafter designated 'Assemblage Development Expts 1 and 2'). We had originally intended to conduct these experiments in Melbourne, but fluctuations in the Sabella spallanzanii population there made such longer-term experiments impossible. The experiments tested the hypothesis that $S$. spallanzanii canopies would cause differences in the abundance of sessile understorey taxa after periods of time considered sufficient for postsettlement interactions to take place. Each experiment consisted of 3 treatments applied to square $400 \mathrm{~cm}^{2}$ PVC plates, which were used as surfaces for the attachment and development of sessile assemblages. The plates were attached to $1.2 \times 0.2 \mathrm{~m}$ PVC tubing frames, which were in turn attached to vertical concrete pilings. Of these pilings, 6 had all fanworms 
removed, while on the other 6 the fanworms were left intact. One plate of each of treatment was attached to each piling in a partially nested or split-plot design. The treatment of cleared vs uncleared pilings tested for effects of the presence of worms on a larger spatial scale than that of the individual settlement plates. Treatments applied to settlement plates were used to test hypotheses about the underlying mechanisms of any effects. These plate-level treatments and their interpretations are described below.

Assemblage Development Expt 1 (10 wk experiment): This experiment was done in summer 1997. Plate level treatments consisted of: (1) 10 Sabella spallanzanii individuals of $9 \mathrm{~mm}$ diameter (density reflected that on surrounding structures) were attached to each plate; (2) 10 mimic fanworms were attached to each plate; (3) plates were bare.

Plate-level treatments were compared to determine whether effects were biological or physical in nature (we assumed that mimics provided identical structure to that of actual fanworms; details of their construction are given in the next paragraph). First, we compared mimics to real worms. If they were different, we concluded that there was a biological effect. In this case we went on to compare mimic and bare plates. If mimic and bare plates were different, we concluded that there was also an effect of physical structure. If the first comparison showed that mimics and worms were not different, we concluded that there was no biological effect, and then compared the mean of the mimic and worm plates with the bare plates. Any difference again indicated a physical effect, while no difference indicated that there was no effect of physical structure.

Sabella spallanzanii used in the experiment were collected from the vertical sides of floating docks adjacent to the experimental pilings less than $1 \mathrm{~h}$ before use, and were kept in containers of fresh seawater. Worms were cleaned of any epibiota by gently scraping the tubes and attached by passing the tubes through holes in the plates. Holes were sized so that the worms fitted snugly. After plates were attached to pilings, the worms quickly resumed feeding, forming a canopy 15 to $20 \mathrm{~cm}$ above the plate surfaces. After a few days of immersion, the worms had glued the bases of their tubes to the back of the plates. Mimic worms were constructed from clear PVC tubing and a 'crown' of jute twine (Kinnears Pty 'Original String', fibre obtained from plants of the family Tiliaceae) was glued in place at 1 end. The fibres of the twine unravelled when submerged to mimic the fine radioles of the fanworms. Mimics were passed through holes drilled into the plates and secured in position with cable ties.

Assemblage development Expt 2 (6 mo experiment): This experiment ran from the start of spring 1997 until the end of summer 1998. The plate treatments used in this experiment were: (1) $10 \mathrm{~S}$. spallanzanii were attached to the plates at the start of the experiment (referred to as '6 mo plates'); (2) plates were left untreated for the first half of the experiment $(3 \mathrm{mo})$, then $10 \mathrm{~S}$. spallanzanii were attached to plates through pre-drilled holes after 3 mo immersion ('3 mo plates'); (3) plates were left untreated for the entire 6 mo ('bare plates').

To control for artefacts of handling during addition of fanworms at the 3 mo stage, plates of all treatments were removed from pilings and placed in containers of seawater; for 6 mo plates, the fanworms were removed and replaced with new individuals.

In this experiment, we were interested in whether the timing of the introduction of Sabella spallanzanii affected the abundance of sessile taxa. Planned comparisons looked first as the difference in density of sessile taxa between the 3 mo plates and the bare plates. If bare and 3 mo plates were different, we concluded that there was an effect of fanworms on the established assemblage, and no further comparison was done. If they were not different, we concluded that there was no effect of adding worms to an established assemblage and went on to compare the means of bare and 3 mo plates to that of the 6 mo plates. If these were different, we concluded that fanworms had an effect on the abundance but that this effect occurred in the first 3 mo. If there was no difference, we concluded that fanworms had no effect at either stage.

Sampling of settlement plates: After each experiment the plates were returned to the laboratory and kept in flowing seawater for a maximum of $7 \mathrm{~d}$ before counting. We placed a grid of $1 \mathrm{~cm}$ squares over each plate and counted the number of individuals in each of 52 squares with the aid of a dissecting microscope. A mat of filamentous algae and detritus formed during the 6 mo experiment, and this was sampled using the intersections of the grid. At each of 104 intersections we scored algal types as present or absent. Detritus attached to the algal filaments was scored in the same way. Each plate was photographed, and the photographs were later examined to determine the area occupied by larger individuals and colonies. Images of each plate were projected onto sheets of paper, and the outline of each colony was traced. These tracings were digitised using a flatbed scanner (Umax Pro Look), and the area of each colony was determined using image analysis software (Sigma Scan, Revision 2.0, Jandel Scientific 1995).

Statistical analysis: Inspection of box plots and residuals revealed that a $\log (x+1)$ transformation improved the homogeneity of variances, and this was used for the entire data set. Results were analysed using analysis of variance (ANOVA), followed by 2 planned comparisons, which examined the effect of the plate treat- 
ments. Because there were very few interactions between plate and piling level effects, main effects only are presented in the tables, with results of any significant interactions given in the text. Error bars for the graphs were computed from the appropriate denominator mean square from the ANOVA test.

The ANOVA for the assemblage development experiments (and for Growth Expt 3: see next subsection) was partly nested, or split-plot, with the presence of absence of worms on pilings ('clearing', 2 levels, fixed), pilings nested within 'clearing', and 'plate type' as the within-plot factor (3 levels, fixed). Two planned comparisons, each with $1 \mathrm{df}$, tested hypotheses (described above) about differences among plate treatments in each experiment. Note that the large number of statistical tests (165: see Tables $1 \& 2$ ) with $\alpha=0.05$ means that it is likely that several statistically significant results occurred by chance (Type I errors).

Because there were few significant main effects in the ANOVA results for Assemblage Development Expt 2 , we calculated the power of these tests. An effect size of $50 \%$ was chosen for the plate treatments, and $100 \%$ was chosen for the clearing treatment. These effect sizes reflect the smallest effects detected in previous experiments (Holloway \& Keough 2002) and Assemblage Development Expt 1 (this study). Effect sizes were log-transformed prior to the calculations. Power was calculated using the Pi-Face add-in program for Microsoft Excel (R. Lenth, University of Iowa, 1996).

Multivariate analysis of the assemblages on each plate was done using the PRIMER software package (Plymouth Marine Laboratories, Version 4.0, 1994). Non-metric multi-dimensional scaling (nMDS) was used, because other parametric techniques make restrictive assumptions about the distribution of the data. We used a Bray-Curtis similarity matrix, and plotted the ordinations separately for plate treatments and clearing treatments. Separate 1-way ANOSIM analyses were done for the clearing and plate treatments. All multivariate analyses were done on untransformed data. The stress values given on ordination plots indicate how well the 2-dimensional plot represents the multivariate relationships among sampling units (settlement panels). Values between 0.1 and 0.2 indicate a usable ordination (Clarke 1993).

Canopy effects on growth and survival. To examine the effect of Sabella spallanzanii canopies on newly settled invertebrates, we measured the growth and survivorship of understorey species in areas with and without canopies. Newly settled sessile invertebrates were collected on $11 \times 11 \mathrm{~cm}$ black Perspex settlement plates. Three experiments were done (hereafter referred to as Growth Expts 1, 2 and 3). For Growth Expt 1, plates were attached to PVC frames and installed on the horizontal undersides of floating docks at the St Kilda Marina for 2 wk from 5 to 19 March, 1998. These dock sections had been cleared of all fanworms. In the second and third experiments, plates were put out nearby at Breakwater Pier, Williamstown (where S. spallanzanii also occurs) for colonisation. Breakwater pier was used as an additional collection site because it experienced high rates of recruitment for a variety of sessile taxa (Keough \& Raimondi 1995). Four week old plates (15 March to 13 April) were used for Growth Expt 2, and $11 \mathrm{~d}$ old plates (7 to 18 May) were used for Growth Expt 3.

Plates were brought back to the laboratory following the colonisation period and kept in flowing seawater for $24 \mathrm{~h}$. The positions of individuals or colonies to be used in the experiments were mapped onto sheets of paper with the aid of a dissecting microscope and a $1 \mathrm{~cm}$ grid placed over the plates. Individuals and colonies were also marked on the plates using a graphite pencil to circle them, allowing easier identification of colonies after the experiment. Each individual or colony was measured, and the method used depended on the species (see following subsections). The plates were returned to the field after mapping and measurements (1 d). Each plate was bolted to the centre of a larger $20 \times 20 \mathrm{~cm}$ plate, which was then attached to a PVC tube frame on the horizontal undersides of floating docks. Each plate sat within $5 \mathrm{~cm}$ of the dock's underside, beneath the fanworm canopy (where present). Plates were assigned to either cleared or worm-covered dock sections (average 270 worms per $\mathrm{m}^{2}$ ). The dock sections used were parallel branches, perpendicular to a central walkway, and were approximately $4 \mathrm{~m}$ apart. The worm-covered sections had an average of 270 fanworms per $\mathrm{m}^{2}$. Fanworms were inserted through holes drilled into backing plates used on worm-covered areas to close up the gap created in the canopy by the attachment of the $20 \times 20 \mathrm{~cm}$ backing plate to the underside of the dock.

Growth Expt 1: The arborescent bryozoan Bugula stolonifera was the subject of the first experiment. All $B$. stolonifera colonies on the plates were used, giving a total of 41 colonies, with 2 to 8 colonies per plate. Three plates were assigned to each of 4 dock sections. Two of the dock sections had been cleared of all fanworms, and the remaining 2 had fanworms intact. Unfortunately, 1 replicate plate was lost, leaving 6 plates on cleared areas and only 5 on uncleared areas. For $B$. stolonifera, colony size was measured as the maximum number of bifurcations. This method has been used by Keough (1986) for B. neritina, and provides a rapid assessment of colony size. $B$. stolonifera, however, also grows by sending out runners across the substratum, which then send up new erect colonies. For B. stolonifera colonies that had grown in this way, we scored each new erect section produced as an addi- 
tional bifurcation of the original colony, with subsequent bifurcations of new colonies being scored also.

Growth Expt 2: We examined the growth and survivorship of the encrusting bryozoan Watersipora subtorquata. Plates had varying numbers of colonies, and a total of 62 colonies were used on 12 plates. Colonies were mapped and marked as for Expt 1. Two plates were assigned to each of 6 floating dock sections, 3 of which had been cleared, and 3 of which had fanworms intact, at the same density as in the first experiment.

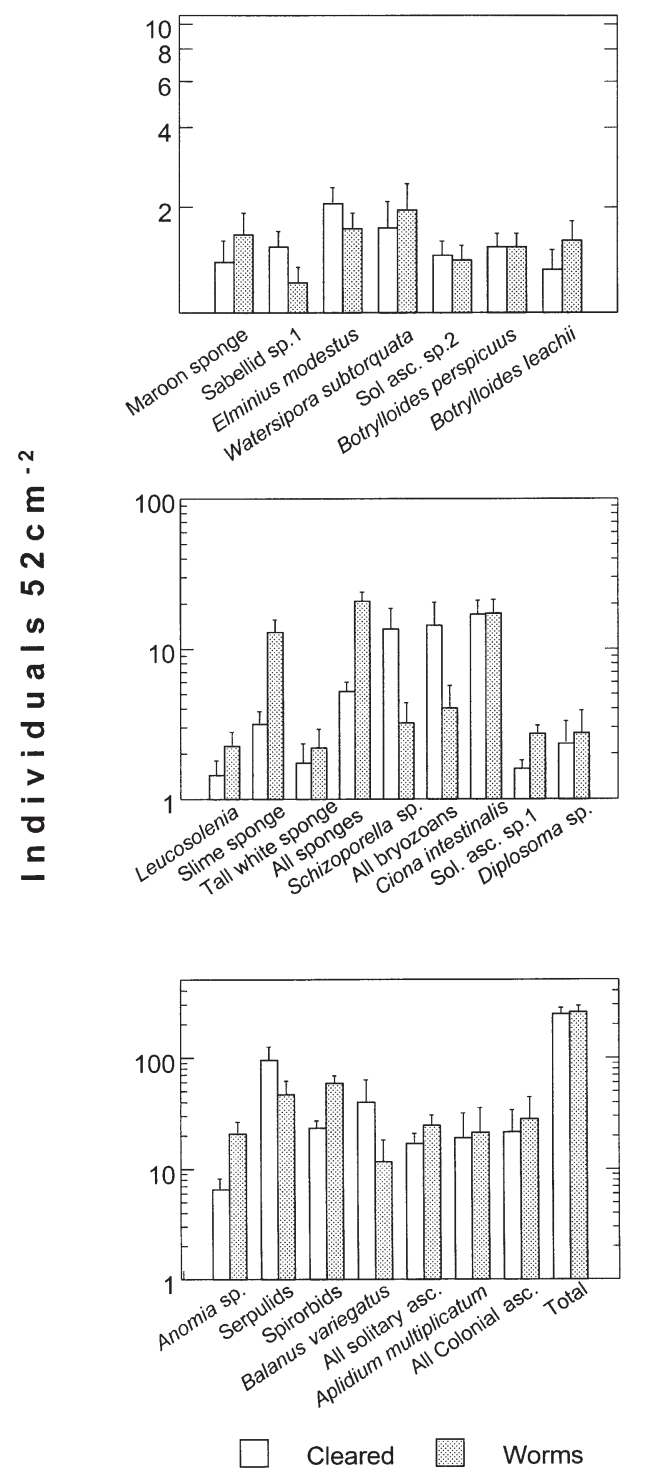

Fig. 1. Assemblage Development Expt 1: recruitment to cleared vs worm Sabella spallanzanii covered pilings after 10 wk at Outer Harbour, South Australia. Unshaded bars: recruitment to cleared pilings; shaded bars: recruitment to worm-covered pilings. Means (pooled across plate treatments) and standard errors (calculated from pooled error term in ANOVA) are shown
The number of zooids was used as a measure of initial and final colony size.

Growth Expt 3: Thirty-six settlement plates were used, and they were assigned to plate treatments as well as to cleared versus uncleared dock sections. The 3 plate treatments used were the same as those in Assemblage Development Expt 1 (i.e. bare, mimic and fanworm-covered plates), with the aim of separating physical and biological effects on growth and survivorship. Three taxa were collected in sufficient numbers for the experiment: Watersipora subtorquata, Bugula stolonifera, and a serpulid polychaete. Animals were mapped and marked as in Growth Expt 1. One plate of each treatment was assigned to each of 12 dock sections. Half of the dock sections (selected randomly) were cleared of all fanworms. Zooids were counted for both the bryozoans, and serpulid polychaetes of the same size (aperture diameter) were chosen at the start of the experiment. A total of 103 W. subtorquata colonies, 365 serpulids and 329 B. stolonifera colonies were used in this experiment.

Analysis of growth and survivorship: Growth of arborescent bryozoans in the first experiment was calculated as the change in number of colony bifurcations. In the second and third experiments, where zooids were counted, growth was calculated as change in zooid number, standardised by the initial number of zooids (i.e. [final-initial]/initial). This standardisation eliminated any correlation between initial size and growth. Growth of serpulid polychaetes was simply the final aperture size, as all were the same size at the beginning of the experiment. Serpulids were measured using an eyepiece micrometer. Survivorship in all experiments was the proportion on each plate still alive at the end of each experiment. Animals that had died were not included in the growth analyses. To avoid the possibility of non-independence within plates, growth data were averaged for plates, and analyses done on these average values in all experiments. Thus plates were the basic units of replication in the analyses.

The results were analysed by analysis of variance (ANOVA). For Growth Expts 1 and 2, the ANOVAs were of a nested design, with 'clearing' (2 levels, fixed) and 'dock section' (random) nested within 'clearing'. For Growth Expt 3, the ANOVA was partly-nested, or split-plot. The analysis and planned comparisons are as described above for Assemblage Development Expt 1.

Where results were non-significant, we calculated the power for 'clearing' effects in all experiments, and for 'plate' effects in Expt 3. An effect size of $25 \%$ of the control (cleared) value was used for the power analyses. The effect size was based on the results of Oka- 
mura (1992), who found a $25 \%$ difference in the growth of an encrusting bryozoan species due to the presence of neighbouring colonies after $4 \mathrm{wk}$ in the field.

\section{RESULTS}

\section{Assemblage Development Expt 1}

The 10 wk assemblage was dominated numerically by serpulid and spirorbid polychaetes, the barnacle Balanus variegatus and the colonial ascidian Aplidium multiplicatum (Fig. 1). A. multiplicatum and the bryozoan Schizoporella sp. were the dominant colonial space occupiers taking up about 25 and $10 \%$ of the available space respectively, with other colonial species combined taking up about 5 to $10 \%$ (Fig. 2). The other species included various encrusting sponges, the bryozoan Watersipora subtorquata, and the colonial ascidians Botrylloides leachi and B. perspicuus. There were no significant interactions between plate and piling treatments in this experiment, therefore the effects of these 2 factors are described separately.

Table 1. Assemblage Development Expt 1. Summary of ANOVA results from 10 wk experiment on effect of Sabella spallanzanii on the recruitment and development of a sessile assemblage on settlement panels at Outer Harbour, South Australia. Where significant effects were found, the direction of the effect is indicated. C: cleared pilings, W: worm-covered pilings. Effect of clearing was tested using the MS 'pile(clearing)' in the denominator, $\mathrm{df}=1,10$, planned comparisons (each with $\mathrm{df}=1,20$ ) were done for plate treatments, using the main error term as the denominator (denom.) MS. Bold indicates significant difference ( $p<0.05$ ). Plates with mimic and real worms were compared (biological effect), and the second comparison (physical effect) depended on the outcome. If mimics and real worms were not significantly different, their mean was compared with bare plates. If mimics and worms were different, bare and mimic plates were compared

\begin{tabular}{|c|c|c|c|c|c|c|}
\hline \multirow[t]{2}{*}{ Species } & \multicolumn{3}{|c|}{ Effect of clearing } & \multicolumn{3}{|c|}{ Planned comparisons for plate-level effects } \\
\hline & MS denom. & $\mathrm{p}$ & Direction & MS denom. & Biological effect & Physical effect \\
\hline \multicolumn{7}{|l|}{ Sponges } \\
\hline Leucoselenia sp. & 0.197 & 0.222 & - & 0.057 & 0.879 & 0.096 \\
\hline Slime sponge & 0.262 & 0.000 & $\mathbf{C}<\mathbf{W}$ & 0.144 & 0.700 & 0.709 \\
\hline Maroon sponge & 0.655 & 0.110 & - & 0.048 & 0.475 & 0.925 \\
\hline Tall white sponge & 0.395 & 0.643 & - & 0.067 & 0.724 & 0.502 \\
\hline All sponges & 0.210 & 0.003 & $\mathbf{C}<\mathbf{W}$ & 0.107 & 0.940 & 0.459 \\
\hline \multicolumn{7}{|l|}{ Polychaetes } \\
\hline Sabellid sp. 1 & 0.013 & 0.006 & $\mathbf{C}>\mathbf{W}$ & 0.022 & 0.684 & 0.247 \\
\hline Serpulids & 0.314 & 0.127 & - & 0.057 & 0.713 & 0.352 \\
\hline Spirorbids & 0.11 & 0.013 & $\mathrm{C}>\mathrm{W}$ & 0.084 & 0.824 & 0.047 \\
\hline \multicolumn{7}{|l|}{ Barnacles } \\
\hline Balanus variegatus & 0.751 & 0.026 & $\mathrm{C}>\mathrm{W}$ & 0.084 & 0.625 & 0.567 \\
\hline Elminius modestus & 0.110 & 0.414 & - & 0.060 & 0.318 & 0.991 \\
\hline \multicolumn{7}{|l|}{ Bivalves } \\
\hline Anomia sp. & 0.276 & 0.017 & $\mathbf{C}<\mathbf{W}$ & 0.127 & 0.317 & 0.128 \\
\hline \multicolumn{7}{|l|}{ Bryozoans } \\
\hline Schizoporella sp. & 0.378 & 0.012 & $\mathbf{C}>\mathbf{W}$ & 0.018 & 0.194 & 0.142 \\
\hline Watersipora subtorquata & 0.209 & 0.666 & - & 0.036 & 0.154 & 0.544 \\
\hline All bryozoans & 0.459 & 0.034 & $\mathrm{C}>\mathrm{W}$ & 0.027 & 0.127 & 0.127 \\
\hline \multicolumn{7}{|l|}{ Ascidians } \\
\hline Ciona intestinalis & 0.204 & 0.970 & - & 0.048 & 0.463 & 0.117 \\
\hline Solitary Ascidian sp. 1 & 0.089 & 0.042 & $\mathbf{C}<\mathrm{W}$ & 0.133 & 0.027 & 0.610 \\
\hline Solitary Ascidian sp. 2 & 0.093 & 0.788 & - & 0.044 & 0.866 & 0.838 \\
\hline All solitary ascidians & 0.344 & 0.787 & - & 0.129 & 0.625 & 0.125 \\
\hline Aplidium multiplicatum & 0.911 & 0.617 & - & 0.065 & 0.703 & 0.759 \\
\hline Diplosoma sp. & 0.410 & 0.744 & - & 0.07 & 0.585 & 0.970 \\
\hline Botrylloides leachi & 0.121 & 0.371 & - & 0.041 & 0.345 & 0.435 \\
\hline Botrylloides perspicuus & 0.093 & 1.000 & - & 0.058 & 0.917 & 0.759 \\
\hline All colonial ascidians & 0.766 & 0.699 & - & 0.05 & 0.726 & 0.645 \\
\hline Total & 0.065 & 0.825 & - & 0.02 & 0.702 & 0.212 \\
\hline \multicolumn{7}{|c|}{ Percent cover of colonial spp. } \\
\hline Aplidium multiplicatum & 1.606 & 0.760 & - & 0.028 & 0.269 & 0.150 \\
\hline Schizoporella sp. ${ }^{\mathrm{a}}$ & 0.453 & 0.018 & $\mathrm{C}>\mathrm{W}$ & 0.046 & 0.618 & 0.139 \\
\hline Other taxa & 0.261 & 0.257 & - & 0.125 & 0.565 & 0.051 \\
\hline Total & 1.320 & 0.983 & - & 0.333 & 0.583 & 0.566 \\
\hline
\end{tabular}



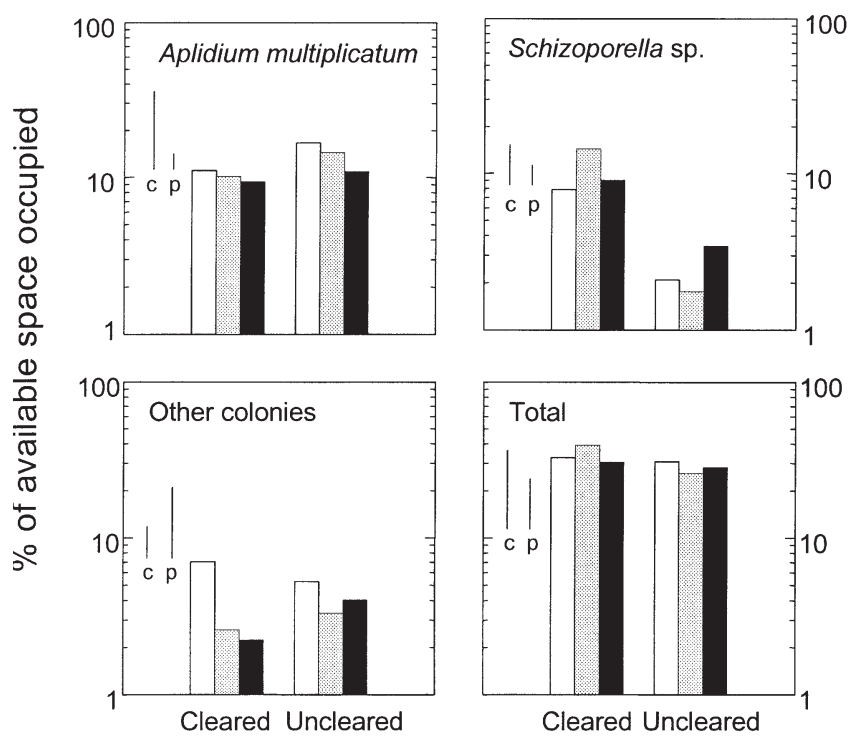

Plate treatments:

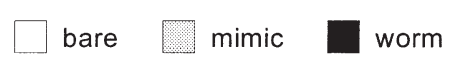

Fig 2. Assemblage Development Expt 1: percent cover of colonial taxa on settlement plates. Error bars are calculated using the denominator mean square from the ANOVA. c: cleared treatments (i.e. comparison of cleared vs uncleared); p: plate-level treatments (i.e. comparison of bare, mimic and worm plates)

Seven individual and 2 grouped taxa ('All bryozoans' and 'All sponges') were significantly affected by the whole-piling clearing treatment (Table 1). Of these, 4 responded negatively to fanworms and 5 responded positively. Recruitment of 'slime sponges' and 'all sponges' were about 4 times higher on worm-covered pilings. The bivalve Anomia sp. was 3 times more abundant in the presence of fanworms, and recruitment of spirorbids and Solitary Ascidian sp. 1 were doubled on the worm-covered pilings (Fig. 1). In contrast, Sabellid sp. 1 was twice as abundant on cleared pilings, while Balanus variegatus, Schizoporella sp. and 'all bryozoans' were all 4 to 5 times more abundant on cleared pilings (Fig. 1). The responses of sponges, spirorbids and barnacles are consistent with those in an earlier, 2 wk experiment at this site (Holloway \& Keough 2002).

Solitary ascidian sp. 1 was the only taxon for which significant biological effects were detected, and recruitment was slightly higher on worm relative to mimic plates (Table 1, Fig. 3). Although statistically significant, the magnitude of this effect was small, representing an increase from about 2 to 3 individuals per plate. Only 1 taxon demonstrated a physical effect (Spirorbids; Table 1), with recruitment on worm and mimic plates about double that on bare plates (Fig. 3).
In contrast, results of a $2 \mathrm{wk}$ experiment showed significant biological effects for sponges, serpulid polychaetes and barnacle taxa (Holloway \& Keough 2002).

Fanworms affected the area occupied by the bryozoan Schizoporella sp., causing a significant interaction between plate and clearing treatments $\left(F_{\text {interaction }}=\right.$ 4.14. $\mathrm{df}=2 ; 20 . \mathrm{p}=0.031$; Fig. 2 ). The interaction was caused by a larger area of Schizoporella colonies on mimic plates attached to cleared pilings, compared to mimics on worm covered pilings. However the areas involved were only about 5 to $10 \%$ of the plate surface (Fig. 2). The proportion of space occupied by Aplidium multiplicatum and other taxa was not affected by the presence of fanworms, nor was the total area occupied by colonial species (Table 1). At the plate scale, there was little effect of worms or mimics on area occupied by colonial species. There was a marginally non-signif-
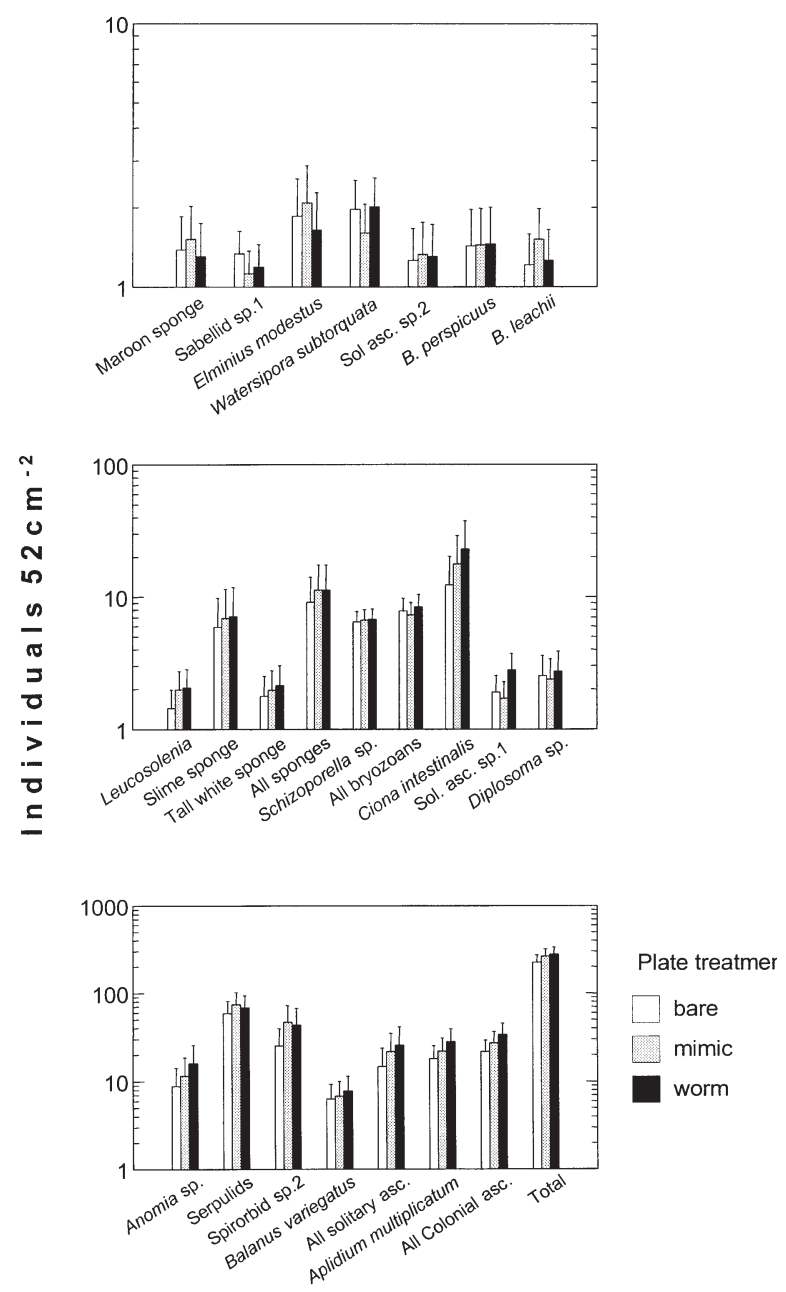

Fig. 3. Assemblage Development Expt 1: recruitment of sessile taxa to 3 plate treatments, pooled across piling treatments, at Outer Harbour. Means (pooled across clearing treatments) and standard errors (from pooled error term in ANOVA) are shown 


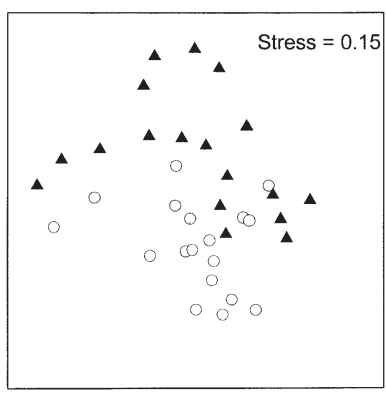

Clearing treatments

- Worms

Cleared

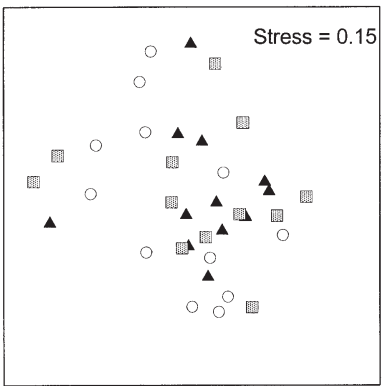

Plate treatments

$\Delta$ Worm

Mimic

Bare

Fig. 4. Assemblage Development Expt 1: nMDS plots of assemblages on settlement plates; each data point represents 1 plate. Plots are identical, but points are coded by clearing treatment (top) and plate treatments (bottom)

icant physical effect on other taxa (Table 1). Therefore, indirect effects of Sabella spallanzanii on other sessile taxa, mediated by competition with colonial species, seem unlikely to be responsible for the observed effects on other taxa.

The nMDS plots show a moderate effect of clearing on assemblage structure (Fig. 4), but there was no discernible pattern for the effect of plate. The results of ANOSIM indicated a significant effect of clearing (global $\mathrm{R}=0.293, \mathrm{p}<0.001$ ) and no physical or biological effects at the plate level (global $\mathrm{R}=0.054, \mathrm{p}=$ 0.96).

\section{Assemblage Development Expt 2}

At the end of the 6 mo experiment, the plates were dominated by several polychaete species, including Filograna implexa, and various unidentified spirorbids (separated on the basis of tube morphology and direction of spiralling; Fig. 5). Unlike the $10 \mathrm{wk}$ experiment, there were few large colonial organisms, and most of the available space was occupied by solitary species. A loose mat of filamentous algae and associated detritus covered about $60 \%$ of the plates' surfaces (Fig. 6), although many sessile species were living underneath the mat. There were few effects of the experimental treatments in the 6 mo experiment despite the generally good power of the tests (Table 2).
At the piling scale, Schizoporella sp. and the combined category of 'All bryozoans' were 4 times less abundant on cleared pilings (Table 2, Fig. 5). The result for 'All bryozoans' reflects that of Schizoporella sp., which was the most abundant species. No other taxa were significantly affected by clearing, and power was high for most taxa.

At the settlement plate scale, 2 taxa ('all sponges' and Filograna implexa) had significant differences between 3 mo and bare plates, indicating an effect of Sabella spallanzanii on their abundance in the developed assemblage (Table 2, Fig. 7). One taxon (Red Filamentous Alga sp. 2) showed significant differences between the 3 and 6 mo plates, indicating an effect of the canopy on this alga in the first 3 mo. Power was high for most taxa, indicating the high probability of detecting effects of the size found in the $10 \mathrm{wk}$ experiment (effect size $=50 \%$; Table 2). One species, Balanus variegatus, showed a significant interaction between

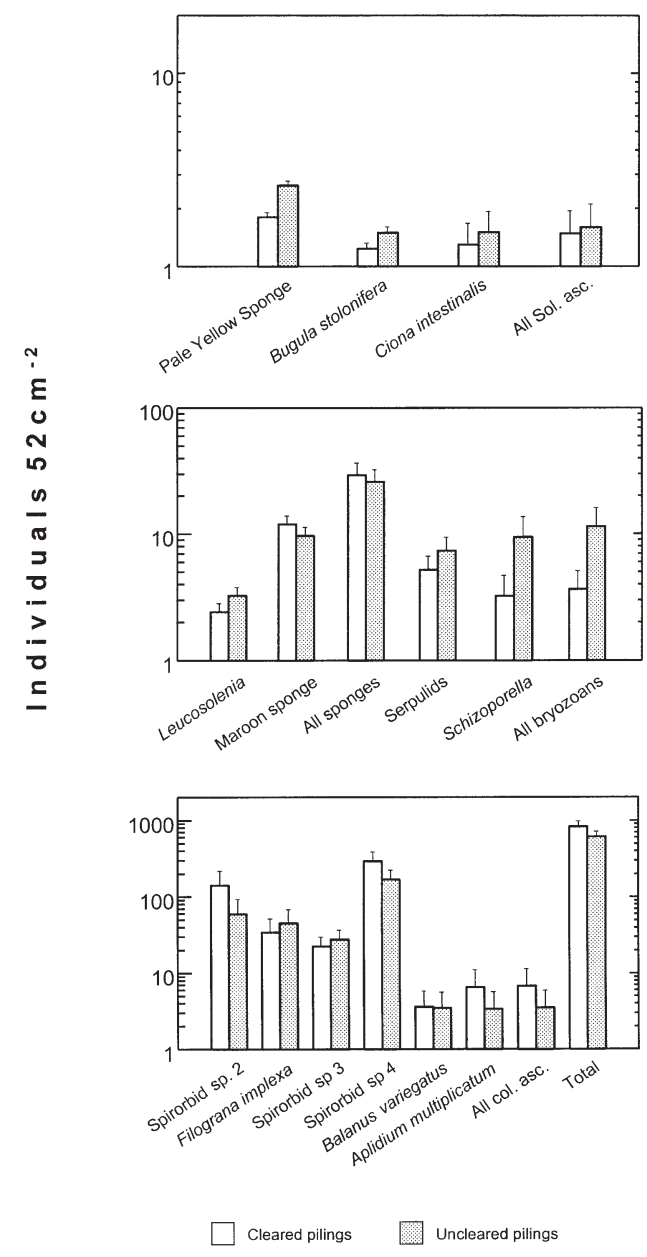

Fig. 5. Assemblage Development Expt 2: density of individuals of various taxa on settlement plates on cleared vs uncleared pilings after 6 mo at Outer Harbour. Means (pooled across plate treatments) and standard errors (from pooled error terms in ANOVA) are shown 
Table 2. Assemblage Development Expt 2: summary of ANOVA results on effect of Sabella spallanzanii on the recruitment and development of a sessile assemblage after 6 mo on settlement panels at Outer Harbour. Where significant effects were found, the direction of the effect is indicated. C: cleared pilings, W: worm-covered pilings. Effect of clearing was tested using the MS 'pile(clearing)' in the denominator, $\mathrm{df}=1,10$; planned comparisons (each with $\mathrm{df}=1,20$ ) were done for plate treatments, using the main error term as the denominator (denom.) MS. Bold indicates significant difference $(\mathrm{p}<0.05)$. Plates with mimic and real worms were compared (biological effect), and the second comparison (physical effect) depended on the outcome. If mimics and real worms were not significantly different, their mean was compared with bare plates. If mimics and worms were different, bare and mimic plates were compared

\begin{tabular}{|c|c|c|c|c|c|c|c|}
\hline \multirow[t]{2}{*}{ Species } & \multicolumn{3}{|c|}{ Effect of clearing } & \multicolumn{4}{|c|}{ Planned comparisons } \\
\hline & MS denom. & $\mathrm{p}$ & Power & MS denom. & p (bare vs 3 mo) & $\mathrm{p}(3 \mathrm{mo}$ vs $6 \mathrm{mo})$ & Power \\
\hline \multicolumn{8}{|l|}{ Sponges } \\
\hline Leucoselenia sp. & 0.212 & 0.117 & 0.87 & 0.124 & 0.347 & 0.127 & 0.06 \\
\hline Slime sponge & 0.242 & 0.000 & 0.78 & 0.08 & 0.545 & 0.458 & 0.11 \\
\hline Maroon sponge & 0.124 & 0.454 & 1.00 & 0.036 & 0.115 & 0.801 & 1.00 \\
\hline All sponges & 0.146 & 0.681 & 1.00 & 0.019 & 0.023 & 0.075 & - \\
\hline \multicolumn{8}{|l|}{ Polychaetes } \\
\hline Filograna implexa & 0.676 & 0.38 & 0.98 & 0.168 & 0.012 & 0.732 & - \\
\hline Other serpulids & 0.248 & 0.724 & 1.00 & 0.067 & 0.113 & 0.058 & 1.00 \\
\hline Spirorbid sp. 1 & 0.824 & 0.724 & 0.41 & 0.134 & 0.599 & 0.075 & 1.00 \\
\hline Spirorbid sp. 2 & 0.703 & 0.211 & 1.00 & 0.119 & 0.099 & 0.702 & 1.00 \\
\hline Spirorbid sp. 3 & 0.376 & 0.666 & 1.00 & 0.192 & 0.378 & 0.200 & 1.00 \\
\hline Spirorbid sp. 4 & 0.249 & 0.180 & 1.00 & 0.057 & 0.525 & 0.437 & 1.00 \\
\hline \multicolumn{8}{|l|}{ Barnacles } \\
\hline Balanus variegatus & 0.848 & 0.962 & 0.47 & 0.125 & 0.306 & 0.308 & 1.00 \\
\hline \multicolumn{8}{|l|}{ Bivalves } \\
\hline Ostrea angasi & 0.088 & 0.427 & 1.00 & 0.013 & 0.889 & 0.376 & 1.00 \\
\hline Anomia sp. & 0.123 & 0.780 & 0.05 & 0.064 & 0.115 & 0.299 & 1.00 \\
\hline \multicolumn{8}{|l|}{ Bryozoans } \\
\hline Schizoporella sp. & 0.28 & 0.032 & - & 0.074 & 0.401 & 0.568 & 1.00 \\
\hline Bugula stolonifera & 0.075 & 0.389 & 1.00 & 0.065 & 0.829 & 0.577 & 1.00 \\
\hline Watersipora subtorquata & a 0.510 & 0.477 & 0.18 & 0.069 & 0.92 & 0.585 & 1.00 \\
\hline Arborescent bryozoans & 0.078 & 0.306 & 1.00 & 0.065 & 0.812 & 0.766 & 1.00 \\
\hline Encrusting bryozoans & 0.520 & 0.080 & 1.00 & 0.083 & 0.551 & 0.762 & 1.00 \\
\hline All bryozoans & 0.392 & 0.038 & - & 0.076 & 0.818 & 0.894 & 1.00 \\
\hline \multicolumn{8}{|l|}{ Ascidians } \\
\hline Ciona intestinalis & 0.038 & 0.680 & 0.74 & 0.041 & 0.489 & 0.281 & 1.00 \\
\hline All solitary ascidians & 0.011 & 0.841 & 0.14 & 0.039 & 0.780 & 0.286 & 1.00 \\
\hline Aplidium multiplicatum & 0.721 & 0.423 & 0.59 & 0.169 & 0.231 & 0.190 & 1.00 \\
\hline All colonial ascidians & 0.73 & 0.413 & 0.62 & 0.184 & 0.307 & 0.218 & 1.00 \\
\hline Total & 0.08 & 0.197 & 1.00 & 0.017 & 0.343 & 0.870 & 1.00 \\
\hline \multicolumn{8}{|l|}{ Algal \% cover } \\
\hline Detritus & 0.215 & 0.786 & 1.00 & 0.134 & 0.93 & 0.165 & 1.00 \\
\hline Green filamentous & 0.295 & 0.323 & 0.93 & 0.023 & 0.662 & 0.722 & 1 \\
\hline Red filamentous sp. 1 & 0.39 & 0.536 & 0.44 & 0.154 & 0.629 & 0.74 & 0.33 \\
\hline Red filamentous sp. 2 & 0.339 & 0.765 & 0.99 & 2.193 & 0.005 & 0.341 & - \\
\hline
\end{tabular}

plate and clearing treatments $\left(F_{\text {interaction }}=4.15, \mathrm{df}=1\right.$, $20, \mathrm{p}=0.03$ ), with slightly higher numbers for bare and 6 mo plates on uncleared pilings, but showing the opposite trend for plates with worms added after 3 mo (Fig. 8).

Inspection of the nMDS plots (Fig. 9) revealed little pattern in the effect of either plate or clearing treatments on the structure of the 6 mo assemblage. ANOSIM found no effect of these treatments either ('clearing': global $\mathrm{R}=0.060, \mathrm{p}=0.08$; 'plate': global $\mathrm{R}=$ $-0.011, p=0.53)$. There was no effect of either clearing (global $\mathrm{R}=-0.015, \mathrm{p}=0.61$ ) or plate treatments (global $\mathrm{R}=-0.015, \mathrm{p}=0.61$ ) on the composition and structure of the algal assemblage.

\section{Growth Expts 1 and 2}

Bugula stolonifera grew much more rapidly on cleared than on uncleared dock sections after $2 \mathrm{wk}$ (Fig. 10), and this difference was highly significant (Table 3). Colonies on some plates experienced nega- 


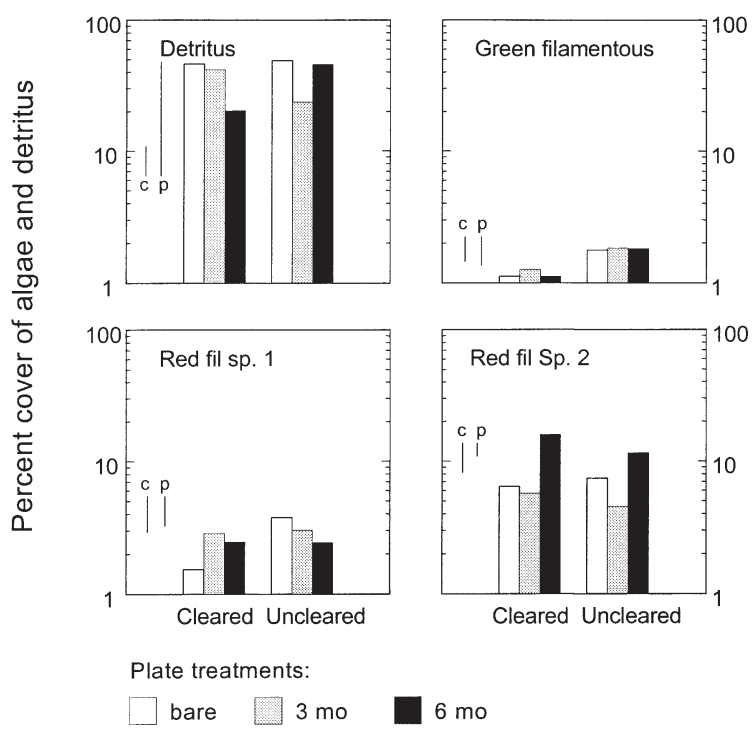

Fig. 6. Assemblage Development Expt 2: percent cover of algal taxa and detritus on settlement plates. Error bars calculated using the denominator mean square from the ANOVA. c: cleared treatments (i.e. comparison of cleared vs uncleared); p: plate-level treatments (i.e. comparison of bare, 3 mo and 6 mo plates)

tive growth under canopies (Fig. 10), i.e. colonies shrank. Survivorship of B. stolonifera was $100 \%$ for all plates on cleared docks relative to about $70 \%$ on uncleared docks (Fig. 10).

There was no effect of the canopy on growth of Watersipora subtorquata (Table 4, Fig. 11), but the power of the experiment was low (Table 4). Survivorship was high for both treatments (Fig. 11), and did not differ significantly.

\section{Growth Expt 3}

Growth of serpulid polychaetes was not affected by either plate or clearing treatments, despite reasonable power. Growth of Bugula stolonifera was significantly affected by clearing treatment (Table 5), but in contrast to the first experiment, growth was higher under canopies than in cleared areas. 'Plate' treatments were not significant for B. stolonifera, but power was low. Watersipora subtorquata growth was not affected by clearing, but again, power was low. W. subtorquata grew more slowly in response to the physical structure on plates (Table 5, Fig. 12). Interestingly there was a trend toward higher growth of all 3 species on uncleared areas (Fig. 12).

Survivorship was high for all sessile taxa, generally above $90 \%$ for the serpulid and Bugula stolonifera, and

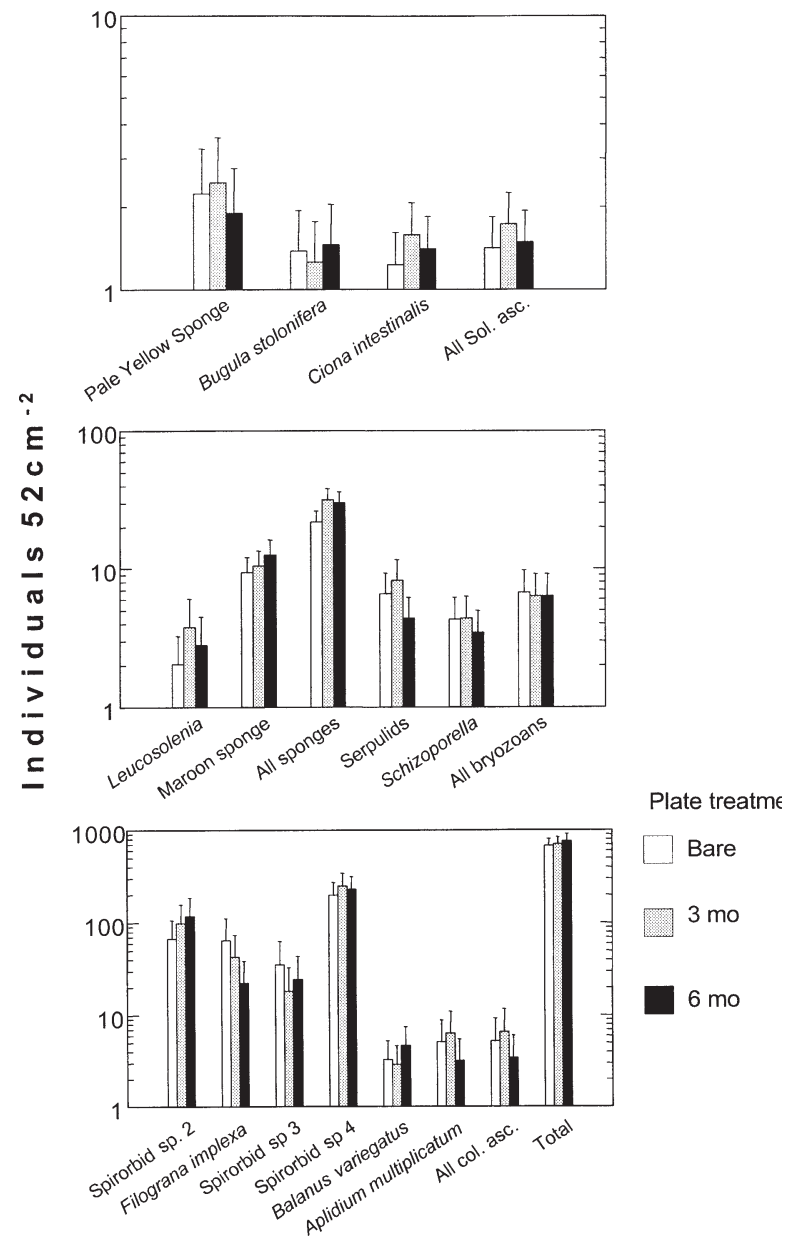

Fig. 7. Assemblage Development Expt 2: density of sessile taxa on plates of 3 different treatments at Outer Harbour. Means (pooled across plate treatments) and standard errors (from pooled error term in ANOVA) are shown

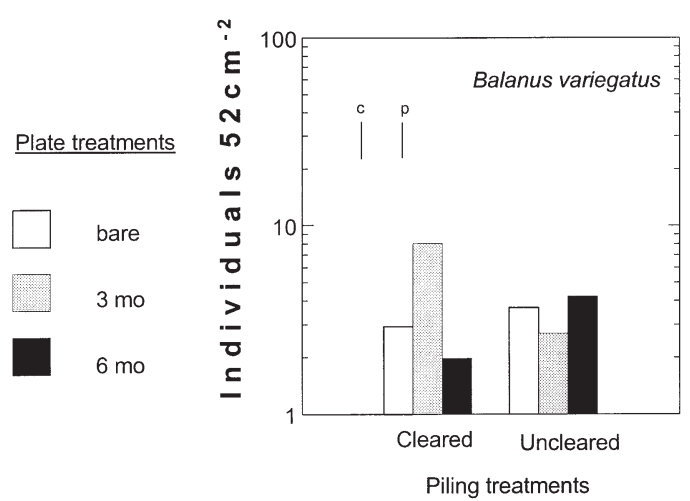

Fig. 8. Assemblage Development Expt 2: effect of Sabella spallanzanii canopy on the abundance of Balanus variegatus. There was a significant interaction between plate and piling treatments. Details of error bars as for Fig. 6 


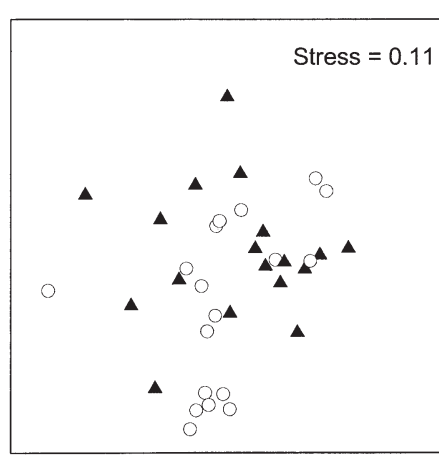

Clearing treatments

- Worms

Cleared

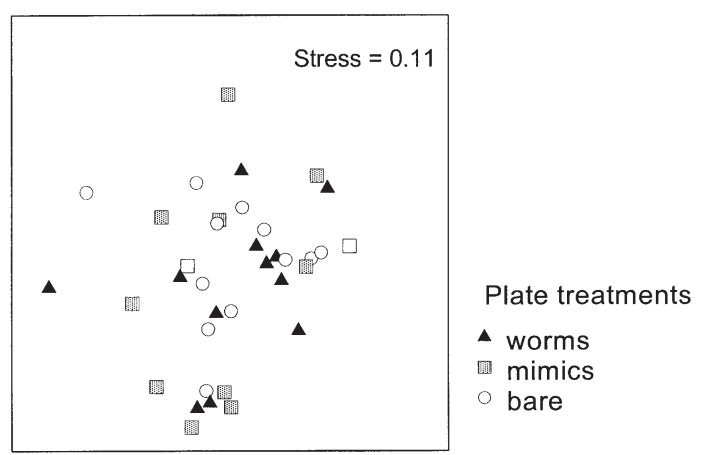

Fig. 9. Assemblage Development Expt 2: 2-dimensional nMDS plots of assemblages on settlement plates; each data point represents 1 plate. Adjacent plots are identical, but points are coded by clearing treatment (top graph) and plate (bottom graph) treatments

Table 3. Growth Expt 1: Bugula stolonifera. ANOVA on effect of clearing and location on growth, as measured by change in the number of bifurcations over $2 \mathrm{wk}$. Bold indicates significant difference $(\mathrm{p}<0.05)$

\begin{tabular}{|lrrrrrc|}
\hline Source & SS & df & MS & F-ratio & p & Power \\
\hline Clearing & 17.911 & 1 & 17.911 & 19.364 & $\mathbf{0 . 0 0 3}$ & - \\
Dock(clearing) & 2.282 & 2 & 1.141 & 1.233 & 0.348 & \\
Error & 6.475 & 7 & 0.925 & & & \\
& & & & & & \\
\hline
\end{tabular}

Table 4. Growth Expt 2: Watersipora subtorquata. ANOVA on effect of clearing and location on growth over $2 \mathrm{wk}$. Growth measured as (final no. zooids initial no. zooids)/initial no. zooids. The power of this experiment to detect a $25 \%$ difference for clearing relative to the uncleared (control) treatment is indicated

\begin{tabular}{|lccccccc|}
\hline Source & SS & df & MS & F-ratio & p & var\% & Power \\
\hline Clearing & 0.178 & 1 & 0.178 & 0.737 & 0.569 & 7.89 & 0.098 \\
Dock(clearing) & 1.855 & 4 & 0.464 & 1.923 & 0.226 & 12.31 & \\
Error & 1.447 & 6 & 0.241 & & & 79.80 & \\
& & & & & & & \\
\hline
\end{tabular}
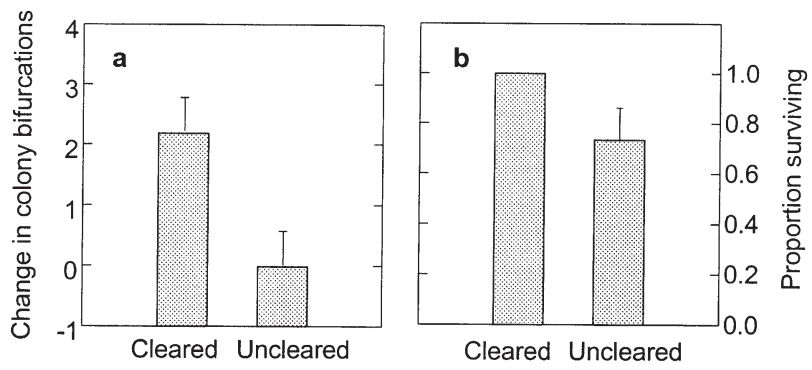

Fig. 10. Growth Expt 1: Bugula stolonifera. Effect of Sabella spallanzanii canopy on average increase in colony size (measured as number of bifurcations) of colonies on settlement plates (a) and average survivorship of colonies on cleared and uncleared dock sections at St Kilda marina (b) over 2 wk. SE bars represent the pooled error term for the clearing effect from the ANOVA

above $80 \%$ for Watersipora subtorquata (Fig. 13). Survivorship of serpulid polychaetes was significantly reduced underneath fanworm canopies (Table 6, Fig. 13). No other treatment effects on survivorship were significant (Table 6).

\section{DISCUSSION}

Resident species have often been shown to affect the recruitment of new individuals into subtidal assemblages over timescales of a few weeks (Osman et al. 1989, Osman \& Whitlatch 1995a,b, Holloway \& Keough 2002). The question of interest here is whether residents (in this case the exotic fanworm Sabella spallanzanii) that can influence recruitment over these relatively short timescales also cause differences over longer time periods.

Effects of fanworms were evident after $10 \mathrm{wk}$ (Assemblage Development Expt 1) at the whole-piling

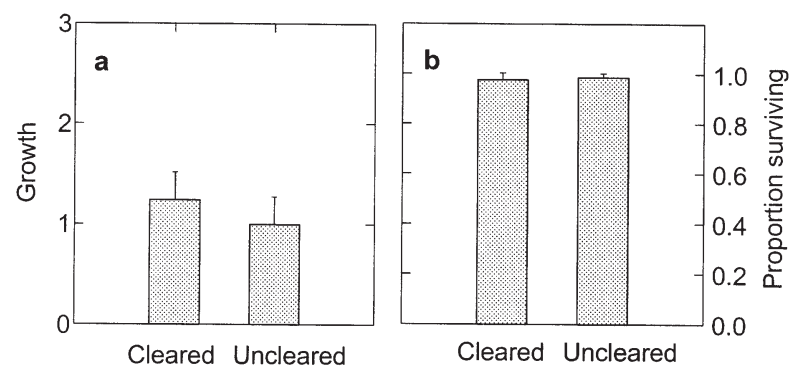

Fig. 11. Growth Expt 1: Watersipora subtorquata. Effect of Sabella spallanzanii canopy on average increase in colony size (a), and average survivorship of colonies on cleared and uncleared dock sections at St Kilda marina (b) over 2 wk. Growth measured as change in number of zooids, standardised for inital zooid number (i.e. [final-initial]/initial). SE bars represent the appropriate pooled error term for the clearing effect from the ANOVA 
Table 5. Growth Expt 3: ANOVA on effect of Sabella spallanzanii canopies on growth of 3 sessile taxa after 4 wk. Power analysis was done for clearing and plate effects where results were not significant. Effect size $=25 \%$ of control value (see text for explanation, end of 'Materials and methods'). Planned comparisons (each with $\mathrm{df}=1,20$ ) were done for plate treatments, using the main error term from the analysis (see 'Materials and methods' for details of hypotheses). Bold indicates significant difference $(\mathrm{p}<0.05)$

\begin{tabular}{|c|c|c|c|c|c|c|c|}
\hline \multirow{2}{*}{$\begin{array}{l}\text { Species } \\
\text { Source }\end{array}$} & \multirow[t]{2}{*}{$\mathrm{df}$} & \multirow[t]{2}{*}{ MS } & \multirow[t]{2}{*}{$F$} & \multirow[t]{2}{*}{$\mathrm{p}$} & \multirow[t]{2}{*}{ Power } & \multicolumn{2}{|c|}{ Planned comparisons } \\
\hline & & & & & & Biol (p) & Phys (p) \\
\hline \multicolumn{8}{|l|}{ Serpulid } \\
\hline Clearing (C) & 1 & 8.977 & 2.116 & 0.176 & 0.708 & & \\
\hline Plate $(\mathrm{P})$ & 2 & 4.960 & 1.193 & 0.324 & 0.886 & 0.318 & 0.262 \\
\hline $\mathrm{C} \times \mathrm{P}$ & 2 & 4.971 & 1.195 & 0.323 & & & \\
\hline Dock(clearing) & 10 & 4.242 & 1.020 & 0.461 & & & \\
\hline Error & 20 & 4.159 & & & & & \\
\hline \multicolumn{8}{|l|}{ Bugula stolonifera } \\
\hline Clearing & 1 & 94.421 & 9.563 & 0.011 & - & & \\
\hline Plate & 2 & 27.112 & 1.897 & 0.176 & 0.063 & 0.347 & 0.990 \\
\hline $\mathrm{C} \times \mathrm{P}$ & 2 & 2.874 & 0.201 & 0.819 & & & \\
\hline Dock(clearing) & 10 & 9.873 & 0.691 & 0.722 & & & \\
\hline Error & 20 & 14.294 & & & & & \\
\hline \multicolumn{8}{|c|}{ Watersipora subtorquata } \\
\hline Clearing & 1 & 3.260 & 0.652 & 0.438 & 0.062 & & \\
\hline Plate & 2 & 9.292 & 4.048 & 0.039 & - & 0.711 & 0.012 \\
\hline $\mathrm{C} \times \mathrm{P}$ & 2 & 2.951 & 1.286 & 0.305 & & & \\
\hline Dock(clearing) & 10 & 4.999 & 2.178 & 0.084 & & & \\
\hline Error & 15 & 2.295 & & & & & \\
\hline
\end{tabular}

scale, with 6 taxa more abundant beneath fanworm canopies, and 3 decreasing in abundance beneath canopies. The effects for barnacles, sponges and bryozoan species were consistent in magnitude and direction with previous experiments on recruitment over 2 wk (Holloway \& Keough 2002). There were few effects of fanworms at the settlement plate scale, sug- gesting that the canopy effect of Sabella spallanzanii on assemblage development may be scale-dependent. Of those plate scale effects that we did observe, 2 were biological and 1 was physical. This is in contrast to findings for recruitment over 2 wk periods in which more than a dozen taxa were affected and the majority of effects were physical (Holloway \& Keough 2002).

Table 6. Growth Expt 3: survivorship. ANOVA on effect of Sabella spallanzanii canopies on survivorship of 3 sessile taxa after 4 wk. Other details as in Table 5. Bold indicates significant difference $(p<0.05)$

\begin{tabular}{|c|c|c|c|c|c|c|c|}
\hline \multirow{2}{*}{$\begin{array}{l}\text { Species } \\
\text { Source }\end{array}$} & \multirow[t]{2}{*}{$\mathrm{df}$} & \multirow[t]{2}{*}{ MS } & \multirow[t]{2}{*}{$F$} & \multirow[t]{2}{*}{$\mathrm{p}$} & \multirow[t]{2}{*}{ Power } & \multicolumn{2}{|c|}{ Planned comparisons } \\
\hline & & & & & & $\operatorname{Biol}(p)$ & Phys (p) \\
\hline \multicolumn{8}{|l|}{ Serpulid } \\
\hline Clearing (C) & 1 & 0.255 & 6.325 & 0.031 & - & & \\
\hline Plate $(\mathrm{P})$ & 2 & 0.064 & 0.844 & 0.445 & 0.999 & 0.247 & 0.613 \\
\hline $\mathrm{C} \times \mathrm{P}$ & 2 & 0.008 & 0.109 & 0.897 & & & \\
\hline Dock(clearing) & 10 & 0.040 & 0.533 & 0.847 & & & \\
\hline Error & 20 & 0.076 & & & & & \\
\hline \multicolumn{8}{|l|}{ Bugula stolonifera } \\
\hline Clearing & 1 & 0.016 & 0.152 & 0.705 & 0.940 & & \\
\hline Plate & 2 & 0.062 & 0.649 & 0.533 & 0.977 & 0.735 & 0.290 \\
\hline $\mathrm{C} \times \mathrm{P}$ & 2 & 0.019 & 0.201 & 0.820 & & & \\
\hline Dock(clearing) & 10 & 0.104 & 1.086 & 0.416 & & & \\
\hline Error & 20 & 0.096 & & & & & \\
\hline \multicolumn{8}{|c|}{ Watersipora subtorquata } \\
\hline Clearing & 1 & 0.323 & 1.141 & 0.311 & 0.255 & & \\
\hline Plate & 2 & 0.193 & 0.790 & 0.468 & 0.407 & 0.350 & 0.405 \\
\hline $\mathrm{C} \times \mathrm{P}$ & 2 & 0.132 & 0.538 & 0.592 & & & \\
\hline Dock(clearing) & 10 & 0.283 & 1.156 & 0.375 & & & \\
\hline Error & 19 & 0.245 & & & & & \\
\hline
\end{tabular}



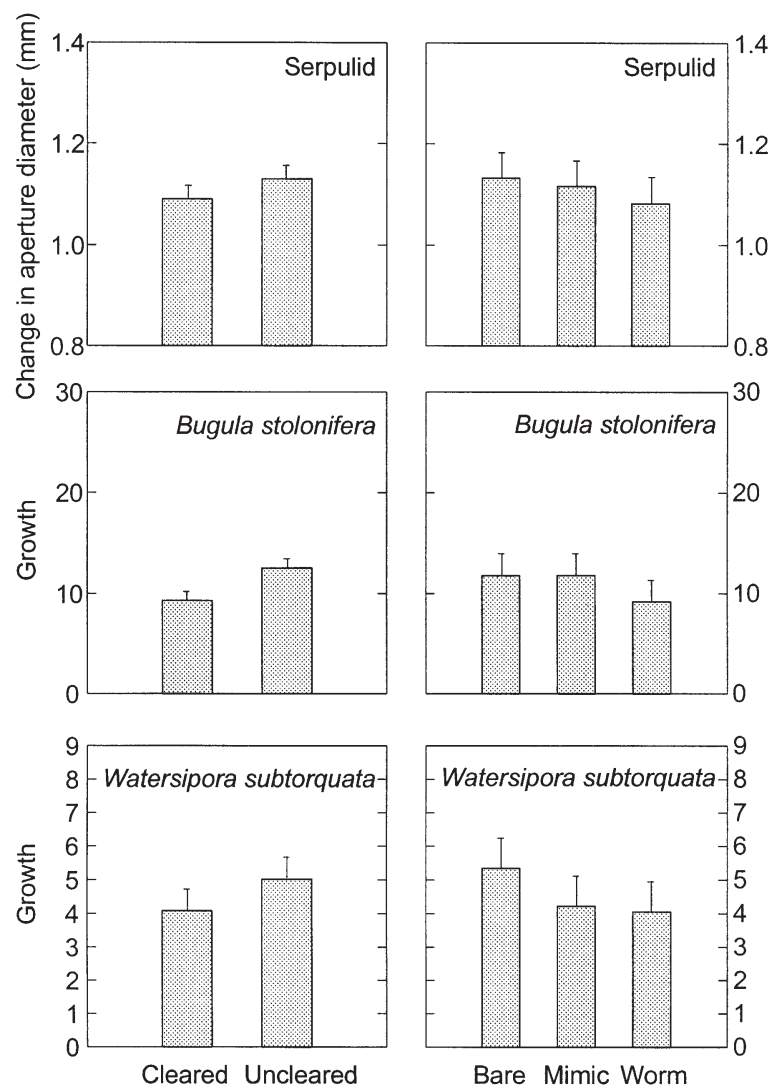

Fig. 12. Growth Expt 3: effects of clearing and plate treatments on growth of sessile taxa at St Kilda after $4 \mathrm{wk}$. Growth measured as the change in aperture diameter for serpulids, and as change in number of zooids standardised for inital zooid number i.e. [final-initial]/initial) for bryozoans. SE bars represent the appropriate pooled error term from the ANOVA

Indirect effects of fanworm canopies on assemblages are possible. For example, potentially competitive species like Aplidium multiplicatum and Schizoporella sp. occupied a considerable amount of the available space on the plates, and therefore may have affected the numbers of other taxa by overgrowing them or preempting space for settlement. While indirect, such effects must still be regarded as impacts of fanworms on particular species - the changes would not occur in the worm's absence. There is no way of knowing whether effects in this study were the result of direct or indirect interactions. For the $10 \mathrm{wk}$ experiment there were differences in the percent cover of Schizoporella sp. between cleared and uncleared areas, but the differences were small, suggesting that this species did not mediate indirect effects of Sabella spallanzanii.

There were few effects of either clearing or plate treatments after 6 mo (Assemblage Development Expt 2), despite high power to detect changes of the size detected in the $10 \mathrm{wk}$ experiment for most taxa. There were 6 statistically significant results in Table 2,
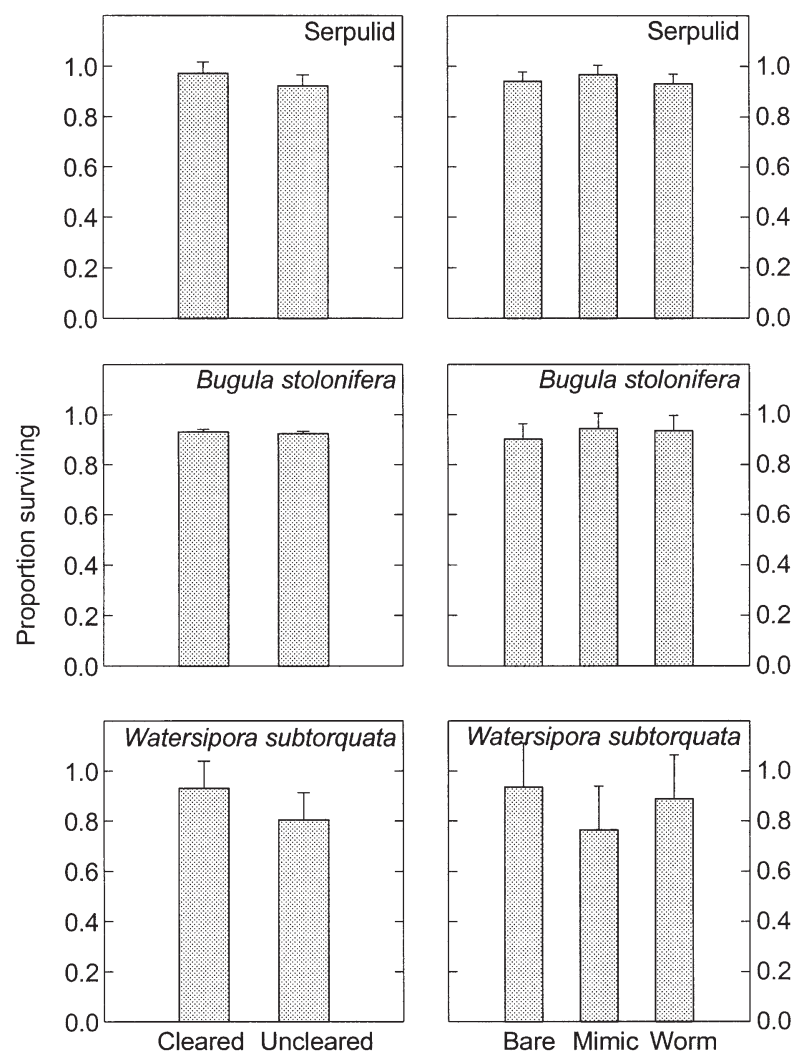

Fig. 13. Growth Expt 3: survivorship. Effects of clearing and plate treatments on survival of sessile taxa at St Kilda. SE bars represent the appropriate pooled error term from the ANOVA

which is not very different from the 4 Type I errors that might be expected across the 81 statistical tests. Other studies on the development of sessile assemblages over extended time periods have found contrasting results with regard to persistence of patterns formed by recruitment. In some cases, early recruits appear to hold the available space against later settlers (e.g. Sutherland \& Karlson 1977). In other cases, early recruits may be replaced by competitively superior species that arrive later (e.g. Dean 1981). Several factors may be important in determining whether early assemblages are found to persist: the species involved, timing of experiments, and duration of experiments.

Whether patterns of recruitment ultimately persist or disappear may depend on the pool of available species and their properties. For example, if a species that is a superior competitor to all others is able to colonise, then that species will inevitably dominate the assemblage (e.g. Dean 1981, Kay \& Keough 1981). Alternatively, if several species are equally competitive, and able to hold the space they occupy, then a number of outcomes or 'multiple stable points' (sensu Sutherland 1974) are possible, depending on which species occupies the space first (e.g. Sutherland \& Karlson 1977). 
So, in order to make predictions about the persistence or otherwise of recruitment patterns in fouling assemblages, it may be important to know the characteristics of the individual species involved, and how they affect recruitment of other species into the assemblage and subsequent assemblage development (Underwood \& Anderson 1994).

In experiments that examine the development of assemblages, the duration or sampling interval of the experiment is vitally important to the results. Differences between assemblages that are apparent over short timescales may be less important over longer periods. Glasby (1998) found that differences between plots tens of metres apart that were apparent after 6 and $10 \mathrm{wk}$ had disappeared after $19 \mathrm{wk}$. Anderson \& Underwood (1994) found that differences in assemblages caused by different substratum materials became less apparent over time. In an investigation on the effect of marinas on assemblage development, Glasby \& Underwood (1998) used 5 and 12 wk periods, and found possible small effects of marinas, but it was unclear whether such effects would be maintained over longer time periods.

There may be several reasons for the disappearance of early recruitment patterns over time. If natural spatial variation in recruitment is related to patchiness in larval supply caused by swarms of larvae (Keough 1983), then temporal variation in the recruitment may be 'averaged out' over time as the chance that individual settlement plates will be exposed to patches of certain species becomes greater. Competition may also be responsible, as available space is filled and species start to compete with each other. If early colonists were short-lived, then natural mortality over time would reduce their abundance.

The disappearance of recruitment patterns over time raises questions about the appropriate timescales over which to examine ecological effects or impacts on sessile assemblages. If effects only manifest themselves over short periods and disappear over longer time periods, are they ecologically important or of concern when managing coastal areas for conservation? Shortterm effects may have implications for particular species under certain circumstances. For instance, shortlived, opportunistic, competitively inferior species that occur mainly in the early stages of assemblage development could be strongly affected, despite a lack of effect in the longer term.

Recruitment of different species can vary independently of one another between seasons and between the same season in different years (Keough 1983), so patterns of assemblage development found in one year may not necessarily be repeatable in other years. For example, Sutherland \& Karlson (1977) found that some distinct assemblages obtained in one year did not occur the following year. In this study, treatment effects were apparent after $10 \mathrm{wk}$ but not $6 \mathrm{mo}$, which is interpreted as meaning that patterns established by early recruitment do not persist as the assemblage develops. This could, of course, be due to the experiments starting at different times. Ideally, experiments should be done over several years in all seasons to determine whether the persistence of recruitment patterns varies among seasons and years.

There was little evidence from the 6 mo experiment that Sabella spallanzanii affected established assemblages. At the plate scale, 'All sponges' and the serpulid Filograna implexa appeared to be affected by the addition of fanworms to the developed assemblage. 'All sponges' were more abundant on both 3 and 6 mo plates than on bare plates (Fig. 7), indicating that fanworms enhanced sponge recruitment into the mature assemblage. This is consistent with our findings in previous experiments (Holloway \& Keough in review), in which fanworms increased recruitment of most sponge taxa, and also with those of others who have found sponges were good invaders of mature assemblages (Sutherland \& Karlson 1977, Kay \& Keough 1981). The abundance of $F$. implexa was decreased by the addition of fanworms. There were no differences between 3 and 6 mo plates, suggesting that the effect of the canopy in the latter part of the experiment was negligible.

Differences in growth and survivorship between canopy and non-canopy treatments demonstrate that canopies can affect sessile taxa post-recruitment. Sabella spallanzanii canopies had variable effects on the growth of sessile suspension feeders. In the first experiment, Bugula stolonifera grew faster on cleared pilings, as might be expected, but in the third experiment colonies under canopies experienced significantly higher growth than their counterparts in the open. The same trend was apparent for Watersipora subtorquata, although the results were not significant (Fig. 12 cf. Fig. 10). Several possible models for this difference in results between the 2 experiments can be proposed. For example, differences in food supply, local current conditions or water temperature could interact with canopy effects to produce different outcomes at different times. There could also be differences in the recruits that were used in the experiments. The quality of recruits may vary among locations or through time within a location. For example if food supply to parents were lower during a period, then the quality of larvae might be lower, leading to recruits that grow more slowly (e.g. Bridges 1996). Whatever the reason for the differences, these results indicate that the effect of canopies on growth is not straightforward, and is in need of further investigation.

Slower growth under canopies, as in Growth Expt 1, is consistent with the findings of several workers who 
found lower growth in the presence of neighbouring suspension feeders (Buss 1981, Okamura 1992, Kim \& Lasker 1997). Competition for food requires that fanworms and other taxa consume the same-sized particles. Little is known about food-size selection in Sabella spallanzanii, but work on other large sabellids shows that they are capable of consuming particles between 2 and $40 \mu \mathrm{m}$ with high efficiency (Dales 1957, Fauchald \& Jumars 1979, Merz 1984). Bryozoans generally consume particles less than $50 \mu \mathrm{m}$, and may concentrate on small flagellates around $10 \mu \mathrm{m}$ (Winston 1977), and serpulids probably feed over a similar particle size range to sabellids (Dales 1957), so dietary overlap is likely to be quite considerable.

Faster growth beneath canopies, as in Growth Expt 3 , is more difficult to explain. Explanations for this phenomenon for bivalves in seagrass canopies suggest that much of their food is derived from algal material resuspended from the substratum (Ambrose \& Irlandi 1992, Judge et al. 1993). Use of resuspended material is an unlikely mechanism for this study, as experiments were done on downward-facing plates, but it is possible that some form of substratum-derived food source could enhance growth beneath Sabella spallanzanii canopies. It is also possible that modifications to the hydrodynamic regime caused by $S$. spallanzanii canopies would enhance the feeding of suspension feeders under certain circumstances. Okamura $(1984,1985)$ found that for both an arborescent and an encrusting bryozoan, feeding rate increased when the ambient flow rates were decreased from $10-12 \mathrm{~cm} \mathrm{~s}^{-1}$ to $1-2 \mathrm{~cm} \mathrm{~s}^{-1}$ in the laboratory. Thus, during periods of high flow or rough weather in the field, S. spallanzanii canopies may be beneficial to the growth of bryozoans by moderating ambient water movement.

Canopies reduced survivorship of sessile taxa on 2 occasions. Survivorship of Bugula stolonifera was lower under canopies in Growth Expt 1, and lower for serpulids in Growth Expt 3. The result for B. stolonifera could be related to food supply, as growth was also lower underneath the canopy in Growth Expt 1. For serpulids, lower survival under the canopy could have been due to lower food supply, but this seems unlikely because there was no difference in growth between cleared and uncleared areas. An alternative explanation for lower survivorship beneath canopies could be increased risk of predation. Fanworms and mimics add structural complexity to the habitat, and this has been shown to increase the abundances of mobile taxa including predatory species (Dean 1981). No motile species were observed on the plates, but they could have been lost during handling.

Differences in growth and survivorship between canopy and non-canopy demonstrates that canopies can have potentially important effects on sessile taxa postrecruitment. Differences in species abundances therefore could have been due to either differential recruitment to canopy versus non-canopy areas, or by differential post-recruitment survivorship in the different areas. This is interesting in light of the fact that there were very few differences after 6 mo. If effects of canopies are variable through time, then it is possible that effects could even out over time, which would explain the lack of clearing effects in the 6 mo experiment.

Residents of sessile assemblages are known to affect the recruitment of later arrivals (Osman et al. 1989, Osman \& Whitlatch 1995a, Holloway \& Keough 2002). However, effects of Sabella spallanzanii canopies of the type observed over 2 and $10 \mathrm{wk}$ periods were not found after 6 mo. This may mean that the effects of S. spallanzanii canopies patterns formed early on in the development of this epifaunal assemblage do not persist for more than a few mo. Alternatively, a different assemblage, less susceptible to the effects of $S$. spallanzanii, may have developed in the 6 mo experiment. The disappearance of apparent impacts after an extended period of time has implications for studies on the ecological effects of exotic species. Observations made over short time periods may not be a reliable indication of longer-term changes, especially in other systems involving very long-lived species (e.g. forests). Further, if alternative assemblage states are possible, then the results of some experiments (on a subset of assemblage states) cannot be generalised to other states, times, or places. Overall, it appears that the impacts of this species on the understorey assemblage may not actually be as great as predicted from shorter-term experiments. In terms of management, such information could be incorporated into risk assessments dealing with this species. We caution, however, that other impacts could possibly emerge later on as assemblages develop further, and that impacts other than those examined here (e.g. effects on nutrient cycles) may occur.

Acknowledgements. Thanks are due to Dr. Jon Havenhand for invaluable logistical support in South Australia. James Doube provided assistance with diving equipment and aquarium space, and Andrew Melville assisted in the field. This work was supported by an Australian Postgraduate Award to M.G H. and an A.R.C. small grant to M.J.K. The manuscript was greatly improved by comments from Dr. Tim Glasby, Dr. Chris McKindsey and 3 anonymous reviewers.

\section{LITERATURE CITED}

Ahn I, Malouf R, Lopez G (1993) Enhanced larval settlement of the hard clam Mercenaria mercenaria by the gem clam Gemma gemma. Mar Ecol Prog Ser 99:51-59

Ambrose WG, Irlandi EA (1992) Height of attachment on seagrass leads to trade-off between growth and survival in 
the bay scallop Agropecten irradians. Mar Ecol Prog Ser 90:45-51

Anderson MJ, Underwood AJ (1994) Effects of substratum type on the recruitment and development of an intertidal estuarine fouling assemblage. J Exp Mar Biol Ecol 184: $217-236$

André C, Rosenberg R (1991) Adult-larval interactions in the suspension-feeding bivalves Crastoderma edule and Mya arenaria. Mar Ecol Prog Ser 71:227-234

André C, Jonsson PR, Lindegarth M (1993) Predation on settling bivalve larvae by benthic suspension feeders: the role of hydrodynamics and larval behaviour. Mar Ecol Prog Ser 97:183-192

Bertness MD (1989) Intraspecific competition and facilitation in a northern acorn barnacle population. Ecology 70: 257-268

Breitburg DL (1985) Development of a subtidal epibenthic community: factors affecting species composition and the mechanisms of succession. Oecologia 65:173-184

Bridges TS (1996) Effects of organic additions to sediment, and maternal age and size, on patterns of offspring investment and performance in 2 opportunistic deposit-feeding polychaetes. Mar Biol 125:345-357

Bros WE (1987) Effects of removing or adding structure (barnacle shells) on recruitment to a fouling community in Tampa Bay, Florida. J Exp Mar Biol Ecol 105:275-296

Brown KM, Swearingen DC (1998) Effects of seasonality, length of immersion, locality and predation on an intertidal fouling assemblage in the northern Gulf of Mexico. J Exp Mar Biol Ecol 225:107-121

Buss LW (1981) Group living, competition, and the evolution of cooperation in a sessile invertebrate. Science 213: 1012-1014

Buss LW, Jackson JBC (1981) Planktonic food availability and suspension-feeder abundance: evidence of in situ depletion. J Exp Mar Biol Ecol 49:151-161

Butler AJ, Connolly RM (1999) Assemblages of sessile marine invertebrates: still changing after all these years? Mar Ecol Prog Ser 182:109-118

Byers JE (2000) Competition between two estuarine snails: implications for invasions of exotic species. Ecology 81: 1225-1239

Carey JM, Watson JE (1992) Benthos of the muddy bottom habitat of the Geelong arm of Port Phillip Bay, Victoria, Australia. Vic Nat 109:196-202

Carlton JT (1989) Man's role in changing the face of the ocean: biological invasions and implications for conservation of near-shore environments. Conserv Biol 3:265-273

Carlton JT, Geller JB (1993) Ecological roulette: the global transport of nonindigenous marine organisms. Science 261:78-82

Clarke KR (1993) Non-parametric multivariate analyses of changes in community structure. Aust J Ecol 18:117-143

Cohen AN, Carlton JT, Fountain MC (1995) Introduction, dispersal and potential impacts of the green crab Carcinus maenas in San Francisco Bay, California. Mar Biol 122: $225-237$

Connell JH (1985) The consequences of variation in initial settlement vs post-settlement mortality in rocky intertidal communities. J Exp Mar Biol Ecol 93:11-45

Crooks JA (1998) Habitat alteration and community-level effects of an exotic mussel, Musculista senhousia. Mar Ecol Prog Ser 162:137-152

Dalby JE (1995) Consequences of aggregated living in the ascidian Pyura stolonifera-evidence for non-contact intraspecific competition. Mar Freshw Res 46:1195-1199

Dales RP (1957) Some quantitative aspects of feeding in sabellid and serpulid fan worms. J Mar Biol Assoc UK 36: 309-316

Dean TA (1981) Structural aspects of sessile invertebrates as organizing forces in an estuarine fouling community. J Exp Mar Biol Ecol 53:163-180

Duggins DO, Eckman JE, Sewell AT (1990) Ecology of understory kelp environments. II. Effects of kelps on recruitment of benthic invertebrates. J Exp Mar Biol Ecol 143:27-45

Eckman JE, Duggins DO (1991) Life and death beneath macrophyte canopies: effects of understory kelps on growth rates and survival of marine, benthic suspension feeders. Oecologia 87:473-487

Eckman JE, Duggins DO, Sewell AT (1989) Ecology of understory kelp environments. I. Effects of kelps on flow and particle transport near the bottom. J Exp Mar Biol Ecol 129:173-187

Fauchald K, Jumars PA (1979) The diet of worms: a study of polychaete feeding guilds. Oceanogr Mar Biol Annu Rev $17: 193-284$

Fréchette M, Bourget E (1985) Food-limited growth of Mytilus edulis in relation to the benthic boundary layer. Can J Fish Aquat Sci 42:1166-1170

Gambi MC, Nowell ARM, Jumars PA (1990) Flume observations on flow dynamics in Zostera marina (eelgrass) beds. Mar Ecol Prog Ser 61:159-169

Glasby TM (1998) Estimating spatial variability in developing assemblages of epibiota on subtidal hard substrata. Mar Freshw Res 49:429-437

Glasby TM (2000) Surface composition and orientation interact to affect subtidal epibiota. J Exp Mar Biol Ecol 248: $177-190$

Glasby TM, Underwood AJ (1998) Determining positions for control locations in environmental studies of estuarine marinas. Mar Ecol Prog Ser 171:1-14

Glynn PW (1973) Ecology of a Caribbean coral reef: the Porites reef-flat biotope. Part II. Plankton community with evidence for depletion. Mar Biol 22:1-21

Holloway MG, Keough MJ (2002) An introduced polychaete, Sabella spallanzanii, affects recruitment and larval abundance of sessile invertebrates. Ecol Appl (in press)

Jackson JBC (1977) Competition on marine hard substrata: the adaptive significance of solitary and colonial strategies. Am Nat 111:743-767

Jackson JBC (1979) Morphological strategies of sessile animals. In: Larwood G, Rosen BR (eds) Systematics Association Special Vol No 11: Biology and systematics of colonial organisms. Academic Press, London, New York, p 499-555

Judge ML, Coen LD, Heck KL (1993) Does Mercenaria mercenaria encounter elevated food levels in seagrass beds? Results from a novel technique to collect suspended food resources. Mar Ecol Prog Ser 92:141-150

Kay AM, Keough MJ (1981) Occupation of patches in the epifaunal communities on pier pilings and the bivalve Pina bicolor at Edithburgh, South Australia. Oecologia 48: 123-130

Keough MJ (1983) Patterns of recruitment of sessile invertebrates in two subtidal habitats. J Exp Mar Biol Ecol 66: $213-245$

Keough MJ (1984a) Effects of patch size on the abundance of sessile marine invertebrates. Ecology 65:423-437

Keough MJ (1984b) Dynamics of the epifauna of the bivalve Pinna bicolor: interactions among recruitment, predation, and competition. Ecology 65:677-688

Keough MJ (1986) The distribution of a bryozoan on seagrass blades: settlement, growth and mortality. Ecology 67:846-857

Keough MJ (1998) Responses of settling invertebrate larvae to 
the presence of established recruits. J Exp Mar Biol Ecol 231:1-19

Keough MJ, Butler AJ (1979) The role of asteroid predators in the organization of a sessile community on pier pilings. Mar Biol 51:167-177

Keough MJ, Raimondi PT (1995) Responses of settling invertebrate larvae to bioorganic films: effects of different types of films. J Exp Mar Biol Ecol 185:235-253

Kim K, Lasker HR (1997) Flow-mediated resource competition in the suspension feeding gorgonain Plexaura homomalla (Esper). J Exp Mar Biol Ecol 215:49-64

McDougal KD (1943) Sessile marine invertebrates of Beaufort, North Carolina. Ecol Monogr 13:321-374

Merz RA (1984) Self generated versus environmentally produced feeding currents: a comparison for the sabellid polychaete Eudistylia vancouveri. Biol Bull 167: 200-209

Okamura B (1984) The effects of ambient flow velocity, colony size, and upstream colonies on the feeding success of bryozoa. I. Bugula stolonifera Ryland, an arborescent species. J Exp Mar Biol Ecol 83:179-193

Okamura B (1985) The effects of ambient flow velocity, colony size, and upstream colonies on the feeding success of Bryozoa. II. Conopeum reticulum (Linnaeus), an encrusting species. J Exp Mar Biol Ecol 89:69-80

Okamura B (1992) Microhabitat variation and patterns of colony growth and feeding in a marine bryozoan. Ecology 73:1502-1513

Osman RW (1977) The establishment and development of a marine epifaunal community. Ecol Monogr 47:37-63

Osman RW, Whitlatch RB (1995a) The influence of resident adults on recruitment: a comparison to settlement. J Exp Mar Biol Ecol 190:169-198

Osman RW, Whitlatch RB (1995b) The influence of resident adults on larval settlement: experiments with four species of ascidians. J Exp Mar Biol Ecol 190:199-220

Osman RW, Whitlatch RB, Zajac RN (1989) Effects of resident species on recruitment into a community: larval settlement versus post-settlement mortality in the oyster Crassostrea virginica. Mar Ecol Prog Ser 54:61-73

Parry GD, Lockett MM, Crookes DP, Coleman N, Sinclair MA (1996) Mapping and distribution of Sabella spallanzanii in Port Phillip Bay. Victorian Fisheries Research Institute,

Editorial responsibility: Roger Hughes (Contributing Editor), Bangor, Wales, UK
Queenscliff Final Report to Fisheries Research and Development Corporation; FRDC Project 94/164

Ruiz GM, Fofonoff P, Hines AH, Grosholz ED (1999) Nonindigenous species as stressors in estuarine and marine communities: assessing invasion impacts and interactions. Limnol Oceanogr 44:950-972

Russ GR (1980) Effects of predation by fishes, competition, and structural complexity of the substratum on the establishment of a marine epifaunal community. J Exp Mar Biol Ecol 42:55-69

Simberloff D (2000) Extinction-proneness of island speciescauses and management implications. Raffles Bull Zool 48:1-9

Sutherland JP (1974) Multiple stable points in natural communities. Am Nat 108:859-873

Sutherland JP, Karlson RH (1977) Development and stability of the fouling community at Beaufort, North Carolina. Ecol Monogr 47:425-446

Talman S, Bite JS, Campbell SJ, Holloway M, McArthur M, Ross DJ, Storey M (1999) Impacts of some introduced marine species found in Port Phillip Bay. In: Hewitt CL, Campbell ML, Thresher RE, Martin RB (eds) Biological invasion of Port Phillip Bay, Victoria. CSIRO Marine Research, Hobart, p 261-274

Todd CD, Keough MJ (1994) Larval settlement in hard substratum epifaunal assemblages: a manipulative field study of the effects of substratum filming and the presence of incumbents. J Exp Mar Biol Ecol 181:159-187

Underwood AJ, Anderson MJ (1994) Seasonal and temporal aspects of recruitment and succession in an intertidal estuarine fouling assemblage. J Mar Biol Assoc UK 74:563-584

Wendt DE (1998) Effect of larval swimming duration on growth and reproduction of Bugula neritina (Bryozoa) under field conditions. Biol Bull 195:126-135

Williamson MH (1996) Biological invasions. Chapman \& Hall, London, New York

Williamson MH (1999) Invasions. Ecography 22:5-12

Winston JE (1977) Feeding in marine bryozoans. In: Woollacott RM, Zimmer RL (eds) Biology of bryozoans. Academic Press, New York, p 566

Young CM, Chia FS (1984) Microhabitat-associated variability in survival and growth of subtidal ascidians during the first 21 days after settlement. Mar Biol 81:61-68

Submitted: March 28, 2001; Accepted: January 15, 2002 Proofs received from author(s): June 14, 2002 